\title{
Quadrupole-Based Mass Spectrometric Evaluation of Isotope Ratios of Carbon Dioxide in Expired Air from Mice and Men Following the Administration of ${ }^{13}$ C-Methyl Methionine
}

\author{
Raymond L. Furner, Renato D. Alarcon, and Tomeko Irving \\ Department of Psychiatry and Behavioral Neurobiology, University of Alabama at Birmingham, \\ Birmingham, Alabama, USA
}

\begin{abstract}
A method is described for the measurement of the isotopic ratio of ${ }^{13} \mathrm{CO}_{2} /{ }^{12} \mathrm{CO}_{2}$ in expired air from individual mice and from humans by means of a quadrupole-based mass spectrometer system. Following the administration of ${ }^{73} \mathrm{C}$-methyl methionine or another appropriately labeled substrate, the ${ }^{93} \mathrm{C}$ portion of the molecule is converted ${ }^{13}{ }^{13} \mathrm{CO}_{2}$. The ${ }^{13} \mathrm{CO}_{2}$ enters the carbonate pool(s) and is ultimately eliminated in the expired air where it is available for analysis. The expired air is transported by a small pump from the subject to a digital valve which provides for the alternate influx of expired air and standard into the mass spectrometer for 30 or 60 seconds each, respectively. The inlet consists of a control valve connected to a microbore stainless steel tube, and can be adjusted manually to achieve a source pressure of $4 \times 10^{-5}$ torr. The correction factors for drift in sensitivity and in the mass axis are generated by repeated, automatic analysis of the running standard and relating those measurements to values generated for the standard during the first minutes of the experiment. Each measurement of an isotopic ratio in expired air is corrected by an amount determined by the standard immediately preceding it. Precision for the measurements of both sample and standard ratios is $\pm 0.2 \%$. The technique should prove useful in assessing the metabolism of substrates that are converted to $\mathrm{CO}_{2}$ and may find utility as a diagnostic tool for certain diseases and metabolic disorders. (J Am Soc Mass Spectrom 1992, 3, 742-749)
\end{abstract}

$\mathrm{I}$ n years past it was claimed that a good diagnostician could identify particular diseases or conditions by smell alone. Unfortunately, not all conditions yield metabolites that are detectable by the human nose, and thus a more sensitive and quantitative method has been sought - one that for certain, suitably labeled substrates, would open a window on the internal milieu.

With the development of ${ }^{14} \mathrm{C}$-labeled substrates it became possible to follow the course of radioactivity through the body. If the radioactive carbon was properly placed within the molecule of interest, the evolution of ${ }^{14} \mathrm{CO}_{2}$ cotuld be followed in the expired air. Although ${ }^{14} \mathrm{C}$ is of minimal hazard, it is not completely without risk either to those who receive it for diagnostic purposes or to those who administer it. Fortunately, similar results are available through the use of ${ }^{13} \mathrm{CO}_{2}$, which is easily measured by means of mass spectrometry.

Address reprint requests to Raymond L. Furner, Department of Psychiatry and Behavional Neurobiology, University of Alabama at Birmingham, UIniversity Station, Birmingham, Alabama 35294.
The first report of breath analysis of ${ }^{13} \mathrm{C}$-enriched $\mathrm{CO}_{2}$ was by Duchesne and van de Vorst in 1968 [1], and was confirmed by Jacobson and co-workers in 1972 [2]. Soon thereafter, the technology was used to evaluate metabolism related to a number of diseases including: cirrhosis [3], fatty acid malabsorption [4], gastric ulcers caused by campylobacter pylori [5], schizophrenia and depression [6], and cancer [7]. Schoeller et al. [8] and Irving et al. [9] have contributed greatly to our understanding of $\mathrm{CO}_{2}$ elimination following bicarbonate infusions and the metabolism of certain labeled carbohydrates. Some of the more rapid metabolic events that occur are not yet well documented or understood because of the difficulty in collecting sufficient numbers of samples of sufficient size to describe them. The reasons behind the limitations are quite clear. The investigators have all used breath collecting devices ranging from cold traps to bailoons to bags to specially designed vacutainers. The purpose has been to carefully quantify the $\mathrm{CO}_{2}$ in expired air while excluding extraneous contributions from the samples themselves or from the surrounding environment. Although the approaches and the results 
in these experiments have been quite good, breath collecting devices have numerous inherent limitations which restrict their application. Specifically, they require cooperation from the subject and a minimum air volume. Thus, they are ill suited to the development of small animal models, and of limited use in the evaluation of children, especially neonates. With the exception of Israelstam et al. [6], who monitored ${ }^{14} \mathrm{CO}_{2}$ continuously in expired air, and Furner et al. [7], who monitored ${ }^{13} \mathrm{CO}_{2} /{ }^{12} \mathrm{CO}_{2}$ ratios in expired air, the analyses were not only off-line, but generally required significant time to accomplish. Thus, the procedures were of little use for diagnosing acute metabolic conditions requiring immediate attention. Today, although the technology has improved, few investigators have ready access to an isotope ratio mass spectrometer and real-time analyses have not been reported until now.

Our objective was to eliminate the requirement for breath collection and fractional distillation prior to the determination of isotope ratios by mass spectrometry. Thus, we have adapted a quadrupole mass spectrometer to provide continuous analysis of ${ }^{13} \mathrm{CO}_{2} /{ }^{12} \mathrm{CO}_{2}$ ratios in expired air from mouse and humans. Samples required are small, and are analyzed on-line without manipulation. The drift in sensitivity reported by Nelson [10] has been corrected through the repeated measurement of the internal, running standard just prior to the sample. Computer algorithms have been developed to correct for the drift in the mass axis. Most important, the results are available for evaluation in hours instead of days. We used ${ }^{13} \mathrm{C}$-methyl methionine as a test substrate to design a mouse model with the ultimate goal of evaluating the report of Israelstam et al. [6] that schizophrenics and depressed patients metabolize methionine in a different fashion than do controls.

\section{Methods}

Theoretical Basis. Under resting conditions the body generates and eliminates $\mathrm{CO}_{2}$ at a relatively constant rate. The primary route of $\mathrm{CO}_{2}$ elimination is in expired air, but losses also occur in urine, feces, and through the skin. ${ }^{12} \mathrm{CO}_{2}$ (yielding $m / z 44$ ) is the predominant isotopic species, comprising nearly $99 \%$ of the total, while ${ }^{13} \mathrm{CO}_{2}$ makes up the balance or slightly over $1 \%$. For our purposes the other isotopic species, while present, are not considered significant, and are not discussed in this report because they will be formed in the same proportion as $m / z 45$ unless there are factors related to the isotope per se that might alter the metabolism. Under normal conditions the ${ }^{13} \mathrm{CO}_{2}$ is produced and eliminated at the same rate as ${ }^{12} \mathrm{CO}_{2}$ (Figure 1). Upon enrichment of the carbon pool with a suitably labeled substrate, the rate of $\mathrm{CO}_{2}$ formation would not be expected to change, but the proportion of ${ }^{13} \mathrm{CO}_{2}$ being formed will increase in proportion to the available substrate. Because the decrease in ${ }^{12} \mathrm{CO}_{2}$ is so

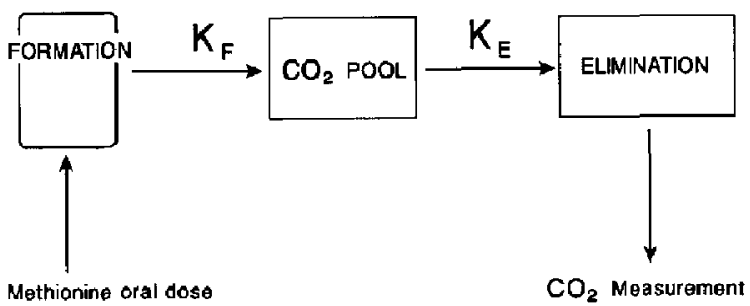

Figure 1. Model for the introduction of the substrate, its conversion to $\mathrm{CO}_{2}$, and its elimination. $\mathrm{K}_{\mathrm{F}}$ represents formation and $\mathrm{K}_{\mathrm{E}}$ elimination of ${ }^{13} \mathrm{CO}_{2}$. More than one rate constant for each is possible for formation and elimination, as indicated by numerical subscripts in the text.

small in comparison with the change in ${ }^{13} \mathrm{CO}_{2}$, we fucus only on the changes in ${ }^{13} \mathrm{CO}_{2}$ and ignore the small increase in the ${ }^{13} \mathrm{CO}_{2} /{ }^{12} \mathrm{CO}_{2}$ ratio that would occur as a result of the correction in ${ }^{12} \mathrm{CO}_{2}$ (see Figure 1).

Instrumentation. Expired air from a mouse or human was sampled at the nose under negative pressure and was drawn via Tygon tubing (i.d. 0.090 in.) to a small pump previously used to oxygenate a fish tank. The air was then directed under positive pressure through Tygon tubing (i.d. $0.090 \mathrm{in}$.) to a T-fitting which served as a pressure control device by venting to atmosphere that portion of the sample not required for analysis. The portion of the sample to be analyzed continued in the Tygon tubing to the digital switching valve. The standard gas mixture for the running standard was also delivered to the switching valve under positive pressure from the tank, and also incorporated the T-fitting for pressure control. The T-fitting prevented a build-up of pressure in the sample line during the time the running standard was being measured and vice versa. A short section $(\sim 50 \mathrm{~cm})$ of fused silica capillary (i.d. 0.01 in.) transported the sample and the analytical standard on an alternating basis from the automatic switching valve (Valco Digital Valve Sequence Programmer, Valco Instruments, Houston, TX) to a Nupro valve (Birmingham Valve and Fitting, Birmingham, AL). The sample or standard entered the control valve through the fused silica capillary and exited to the mass spectrometer source through microbore stainless steel tubing commonly used in high performance liquid chromatography (o.d. 0.06 in.; i.d. $0.01 \mathrm{in}$.). The microbore tubing was welded inside a larger stainless steel tube (o.d. 0.25 in.; i.d. 0.082 in.) to match the inlet port of the HP 5985 mass spectrometer A schematic of the inlet is shown in Figure 2. The probe tip was positioned approximately $2 \mathrm{~cm}$ from the source, which resulted in a maximum signal for $\mathrm{CO}_{2}$. The mass spectrometer was an HP 5985B quadrupole system (a gift from Texaco, Inc., Port Arthur, TX) with the inlet from the gas chromatograph plugged. The source temperature was maintained at $200{ }^{\circ} \mathrm{C}$, and the manifold at $140^{\circ} \mathrm{C}$. The source pressure was main- 


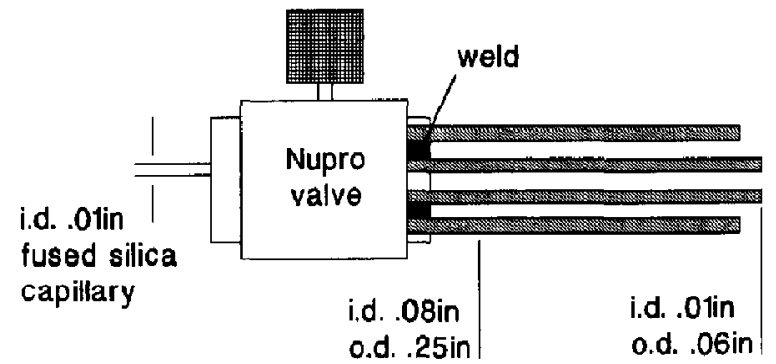

Figure: 2. Inlel probe designed lu bleed gids into the HP5985 mass spectrometer.

tained at $4 \times 10^{-5}$ torr by means of the Nupro control valve. Some mixing of the sample was inevitable, but such mixing as occurred appeared to cause no problem in the measurement of the isotopic ratios.

Data Collection. Data were collected in the selected ion monitoring mode using an HP1000 series computer under the control of Answer Software. Mass-to-charge ratios and measuring, or dwell, times were as follows: $m / z 40.0\left(\mathrm{Ar}^{+}\right), 50 \mathrm{~ms} ; m / z 44.0\left({ }^{12} \mathrm{CO}_{2}^{+}\right), 50 \mathrm{~ms} ; \mathrm{m} / \mathrm{z}$ $45.0\left({ }^{13} \mathrm{CO}_{2}^{+}\right), 50 \mathrm{~ms} ; \mathrm{m} / z 600.0$ (dummy mass), 450 $\mathrm{ms}$. Total scan time was $600 \mathrm{~ms}$. Argon is found in ambient air at a concentration of about $1 \%$, whereas it was of much lower concentration in the standard. This made argon an inexpensive marker for use in the data reduction algorithm to determine whether sample or standard was being measured. The ion of $\mathrm{m} / \mathrm{z}, 600.0$ was measured to provide a time-out or rest period for the mass spectrometer to prevent excessive loss of sensitivity and to help maintain machine stability; essentially no ions were detected during this time. Experiments were conducted for up to $4 h$ with mice or humans. Approximately 15,000 data points were collected, each consisting of individual abundances (digitized signal) for the four masses described above.

A mixture of $\mathrm{N}_{2}: \mathrm{CO}_{2}$ (95:5) was purchased locally from AirCo Medical Gas Products. Dilution (1:2) with compressed air that was low in argon $(<0.2 \%)$ provided a mixture with a $\mathrm{CO}_{2}$ concentration of approximately one-half the maximum of that occurring in mouse or human breath during exhalation.

As shown in Figure 3 the instrument was not stable with respect to sensitivity because the apparent abundance of argon in ambient air declined over time. The isotopic ratio determined for the running standard also changed over time, as shown in Figure 4. Continuous corrections were made to the data by measuring the standard for $30 \mathrm{~s}$ and the sample for $60 \mathrm{~s}$ in alternating fashion, as shown in Figure 5 . What appears to be noise in the $\mathrm{CO}_{2}$ measurement is actually the result of changes in the $\mathrm{CO}_{2}$ concentration that occur during the breathing cycle. Relatively smooth portions of the same trace represent the measurement of the running standard that is described below. Notice that ${ }^{13} \mathrm{CO}_{2}$ and ${ }^{12} \mathrm{CO}_{2}$ change in very similar fashion. However, small

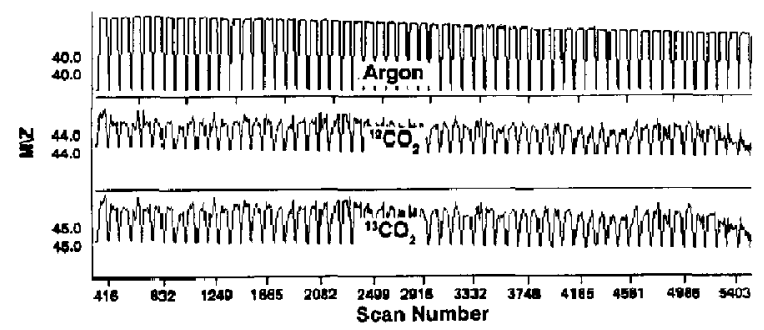

Figure 3. Raw data demonstrating the decline in sensitivity wver time. The apex of each peak represents the sample; the nadir represents standard. Sample gas was monitored for $60 \mathrm{~s}$ and the standard for $30 \mathrm{~s}$. Numbers at the bottom are scan numbers, each of which represents approximately $600 \mathrm{~ms}$. Numbers directly above the mass represent the maximum signal for that mass during the experiment; all values are normalized for graphic presentation. Trace $A$ is the selected ion monitoring profile of $\mathrm{Ar}^{+}$of $m / 240.0$; Trace $\mathrm{B}$ of ${ }^{12} \mathrm{CO}_{2}$. of $m / z 44.0$; Trace $\mathrm{C}$ of ${ }^{13} \mathrm{CO}_{2}$. of $\mathrm{m} / z 45.0$.

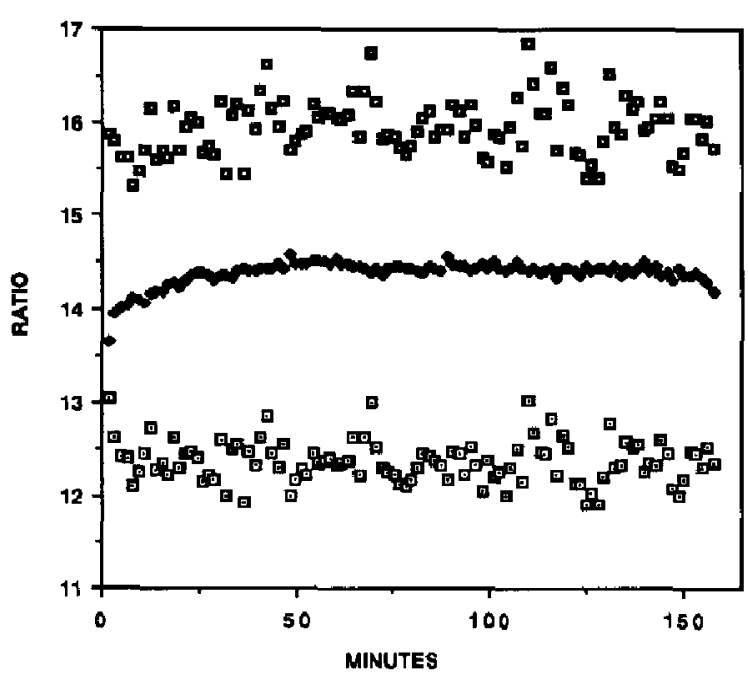

Figure 4. Ratios of ${ }^{13} \mathrm{CO}_{2} /{ }^{12} \mathrm{CO}_{2}$ in untreated human control demonstrate the need for correction of the data because the running standard does not have zero slope. (a) Uncorrected ratios for expired air; ( ) uncorrected ratios for standard; $(\square)$ corrected ratios for expired air. Calculations shown in the text.

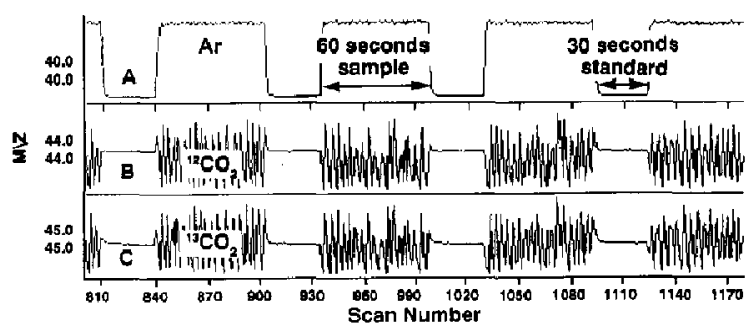

Figure 5. Raw data from Figure 3, expanded to show detail. Sample gas was monitored for $60 \mathrm{~s}$ and the standard for $30 \mathrm{~s}$. Numbers direclly above the mass represent the maximum signal for that mass during the experiment; all values are normalized for graphic presentation. Trace $A$ is the selected ion monitoring profile of $\mathrm{Ar}^{+}$of $m / z 40.0$; Trace $\mathrm{B}$ of ${ }^{12} \mathrm{CO}_{2}+$ of $m / z$ 44.0; Trace $\mathrm{C}$ of ${ }^{13} \mathrm{CO}_{2}$. of $m / z 45.0$. 
quantitative differences are generated following the administration of ${ }^{13} \mathrm{C}$-labeled substrate, and those changes are described below.

Data Redurtion. An algorithm was developed to utilize the data such that each corrected ratio for the sample would be related to values for a corrected standard ratio immediately preceding it. The average ratio for the analytical standard, 5 minute standard, was determined over the first 5 minutes of the experiment. Then the 5 minute standard ratio was divided by the absolute standard for ${ }^{13} \mathrm{CO}_{2} /{ }^{12} \mathrm{CO}_{2}$, which provided a correction factor for the day-to-day variation in the machine.

\section{5 min standard/absolute standard$$
\text { = corrected } 5 \text { min standard }
$$

During the experiment a $30-\mathrm{s}$ measurement of the running standard preceded the 60-s measurement of sample. The corrected 5 minute standard divided by the running standard was termed the drift factor, which was aimed specifically at the drift in sensitivity and the shift in mass axis during the course of the experiment.

$$
\begin{aligned}
& \text { corrected } 5 \mathrm{~min} \text { standard/running standard } \\
& =\mathrm{drift} \text { factor }
\end{aligned}
$$

The sample ratio was multiplied by the drift factor (eq 2 ), resulting in a corrected sample ratio.

sample ratio $\times$ drift factor $=$ corrected sample ratio (

The standard used is sufficient provided that the changes in the sample are considered in relative rather than absolute terms, and provided that the measurements of the two masses ( $m / z 44$ and 45 ) are independent. In this report there is no attempt at quantitative analysis, the measurements are independent and the relationship between the two masses within the time period measured is a constant (data not shown). Further support for the linearity of measurement and the applicability of the standard is that the formation and elimination of $\mathrm{CO}_{2}$ is the sum of two or more exponential functions described in eq 4 , and each of these functions can be described in a log linear fashion.

Corrected data were multiplied by 1000 to facilitate inspection. The initial values for the 5 minute standard (eq 1) were correcled to a nominal absolute value to account for daily variation in machine performance because exact ratios for ${ }^{13} \mathrm{CO}_{2} /{ }^{12} \mathrm{CO}_{2}$ were not available with the system. The running standard ratio, which was measured over $30 \mathrm{~s}$, was constantly corrected to initial conditions, as described in eqs $1-3$, and the drift factor was used to adjust the sample ratio, which was the average of acceptable ratios that were measured during $60 \mathrm{~s}$. Because the abundance available for measurement affected the ratios, accept- able ratios were generated from those individual spectra with abundance less than the dynamic range $(\sim 32,760)$ while those in excess of that amount were eliminated from the calculation. Spectra for which the abundance for ${ }^{13} \mathrm{CO}_{2}$ was $20 \mathrm{u}$ or less were also eliminated from the calculation.

Plammacokinetics. Raw data were extracted from the files and reduced to averages and corrected ratios by means of a program written in BASIC especially for that purpose. The reduced data were transferred manually to an Apple SE computer equipped with a graphics package, statistical programs, and a spread sheet. Analysis of variance, standard error, and mean values were determined to assure reproducibility. The data were plotted, and a nonlinear regression was performed on selected terminal segments of the data. Curve stripping was accomplished manually with the help of the spread sheet. The process was repeated as needed to generate terms with which to express the model as follows:

$$
\mathrm{R}=-\mathrm{Ae}_{\mathrm{F} 1^{t}}^{-\mathrm{K}}-\mathrm{Be}_{\mathrm{E2} 2^{1}}^{-\mathrm{K}}+\mathrm{Ce}_{\mathrm{E} 1^{1}}^{-\mathrm{K}}+\mathrm{De}_{\mathrm{E} 2^{t}}^{-\mathrm{K}}
$$

$R$ is the ratio of ${ }^{13} \mathrm{CO}_{2} /{ }^{12} \mathrm{CO}_{2}$ at time t. $\mathrm{A}, \mathrm{B}, \mathrm{C}$, and $\mathrm{D}$ are intercept values. $\mathrm{K}_{\mathrm{F} 1}$ and $\mathrm{K}_{\mathrm{F} 2}$ represent the rates of change in the ratio of ${ }^{13} \mathrm{CO}_{2} /{ }^{12} \mathrm{CO}_{2}$ in the expired air during the time that the concentration of ${ }^{13} \mathrm{CO}_{2}$ is increasing in the expired air. $\mathrm{K}_{\mathrm{F} 1}$ and $\mathrm{K}_{\mathrm{F}_{2}}$ are rates of change in the ratio of ${ }^{13} \mathrm{CO}_{2} /{ }^{12} \mathrm{CO}_{2}$ in the expired air during the time that the concentration of ${ }^{13} \mathrm{CO}_{2}$ is declining. It is critical to remember that changes in the expired air merely reflect events that have recently occurred in the body. While not all terms are found in each experiment, the model is still the simplest one that is applicable to all of the experiments. Optimizing the fit was not attempted, although in most cases several attempts were made to eliminate obvious errors. Better curve fitting procedures will provide a basis for modifying the experimental design of future experiments. Fitted data were generated by means of the spread sheet, and are shown for comparative purposes.

Mouse Studies. Female Charles River mice weighing approximately $23 \mathrm{~g}$ were purchased from Jackson Labs and housed in shoe-box cages until used in the experiment. BALB/c mice, control and genetically deficient, were raised in a pathogen-free environment in University facilities. There were four mice used per experiment except in the case of $\mathrm{BALB} / \mathrm{C}$, where only one experimental and one control mouse were available. A restraining chamber was fabricated from a 50 $\mathrm{ml}$ syringe [11] that was modified with a conical projection on the nipple end which was perforated to allow the influx of air under vacuum. The cone was strategically designed such that the mouse received adequate air only when the nose was inserted into the cone. The sampling line from the pump was attached 
to the end of the cone. Air flow from the tip of the cone was approximately $60 \mathrm{ml} \mathrm{min}{ }^{-1}$ (approximately three times the minimum required by a mouse) and was provided by a small pump previously used in a fish tank. Air was transported from the chamber to the pump under negative pressure, and then to the inlet valve of the mass spectrometer under slight positive pressure. Positive pressure at the inlet was essential in maintaining proper source pressure.

On the day of the experiment a mouse was selected, weighed, and placed in the restraining chamber for approximately $15 \mathrm{~min}$ to allow initial accommodation to the chamber, and thus reduce random "escape-activity" during the experiment. Following the accommodation phase, baseline data were collected for $15 \mathrm{~min}$. The mouse was then removed from the chamber and dosed intraperitoneally (i.p.) or orally (p.o) with ${ }^{13} \mathrm{C}$-methyl methionine, $90 \%$ enriched from Merck Isotopes (Montreal, Canada). Dosing generally required no more than $30 \mathrm{~s}$. High doses were $350 \mathrm{mg} / \mathrm{kg}$ and low doses were $175 \mathrm{mg} / \mathrm{kg}$ given in 300 and 200 $\mu l$ of deionized water, respectively. After dosing, the animal was returned to the chamber and its expired air was monitored for up to $4 \mathrm{~h}$. Animal cxperiments were approved by the Institutional Review Board at the University.

Human Studies. One control male with no known pathology and one femalc subject diagnosed as manic-depressive, or bi-polar, were referred to the study from the clinical units of the Department of Psychiatry and Behavioral Neurobiology. The nature of the study was explained to them, and they signed a consent form prior to being entered into the study. The subjects were requested not to eat for $12 \mathrm{~h}$ prior to the experiment. A brief personal history was taken to complement the medical history available from the subject's chart. The ${ }^{13} \mathrm{C}$-methyl methionine, $99 \%$ enriched, was purchased from Merck Isotopes and was checked for pyrogens prior to dispensing by the University Hospital Pharmacy. After 15 min of collecting baseline data, the subject was asked to drink a solution containing $1 \mathrm{~g}$ of ${ }^{17} \mathrm{C}$-methyl methionine in $100 \mathrm{ml}$ deionized water followed by $50 \mathrm{ml}$ of plain water. Human experiments were approved by the Institutional Review Board of the University and by the Food and Drug Administration under IND 24835.

For breath collection, a two-prong nasal cannula was inserted into the nostrils and connected to the pump, as described above. Constant sampling rather than quantitative collection was the objective. No attempt was made to measure the total volume of expired air or the concentration of $\mathrm{CO}_{2}$ contained therein. The objective was to monitor relative changes in the ratio of ${ }^{13} \mathrm{CO}_{2} /{ }^{12} \mathrm{CO}_{2}$ as they occurred following the administration of ${ }^{13} \mathrm{C}$-labeled methionine. Subjects were monitored up to $4 \mathrm{~h}$ after dosing. During that time movement was allowed, but was not encouraged.

\section{Results}

Control experiments with untreated subjects (both mice and humans) were conducted to define the parameters for the experiments described above. Sensitivity was adjusted by changing voltages for the repeller, $x$-ray, or electron multiplier to assure an adequate signal corresponding to the concentration of ${ }^{13} \mathrm{CO}_{2}$ while the signal for ${ }^{12} \mathrm{CO}_{2}$ remained within the dynamic range. The mass axis was calibrated manually to $m / z 44.0$ by using the diluted $\mathrm{N}_{2}: \mathrm{CO}_{2}$ as the calibration standard at a source pressure of $4 \times 10^{-5}$ torr.

We found that the sensitivity changed with time (see Figure 3), and also that the mass axis shitted (or drifted) as shown in Figure 4 . Note that for uncorrected data in Figure 4 the ratios for both the running standard and the sample increased over time. While sample composition from a living subject might be expected to change for a variety of reasons, the ratio obtained from the standard must remain the same. In earlier experiments (not shown here) the drift in ratio was not predictable as to direction or magnitude, and attempts at using other gases including argon as standards were unsuccessful. Because the reasons for the changes were never completely explained, the corrections were designed to compensate for both sensitivity and stability regardless of the direction of the correction required. Fortunately, the drift in sensitivity and the change in ratio can be corrected with the application of the appropriate correction factors, as described above. With the measurement of 30 independent ratios, the precision for the measurement of an average ratio for the uncorrected sample of expired air from a mouse was $12.369 \pm .028$ (mean \pm standard error (SE). $\mathrm{n}=30$ ); the uncorrected running standard ratio was $11.597 \pm .023$ (mean $\pm \mathrm{SE}, \mathrm{n}=30$ ). Variations in the ratio within a series of measurements were about $0.2 \%$. Over the course of an experiment the corrected average ratios were quite consistent. For a human control sample the ratio was $12.362 \pm 0.022$ (mean $\pm \mathrm{SE}, \mathbf{n}>$ 60), and for control mice $12.238 \pm 0.010$ (mean $\pm \mathrm{SE}_{r}$ $\mathrm{n}>60$ ). Data from an untreated human control are shown in Figure 4. As with the discrete measurements, the precision is about $\pm 0.2 \%$.

In mice that received the low dose of ${ }^{1.7} \mathrm{C}$-methylmethionine orally (Figure 6), the corrected values for the predosing phase were not different from those of control mice during the same period. The ratio of ${ }^{13} \mathrm{CO}_{2} /{ }^{12} \mathrm{CO}_{2}$ increased exponentially after oral dosing, and the maximum change occurred within 15 to $20 \mathrm{~min}$. After reaching a maximum the decline in the ratio was also exponential and consisted of three phases for mice in this particular experiment. The results from the low dose $(175 \mathrm{mg} / \mathrm{kg})$ of methionine given intraperitoneally (Figure 7) were similar although the isotope ratio changed more with the i.p. dose, and there was only one phase of elimination instead of two. As expected, the high duse of methionine ( 350 $\mathrm{mg} / \mathrm{kg}$ ) (data not shown) produced much greater 


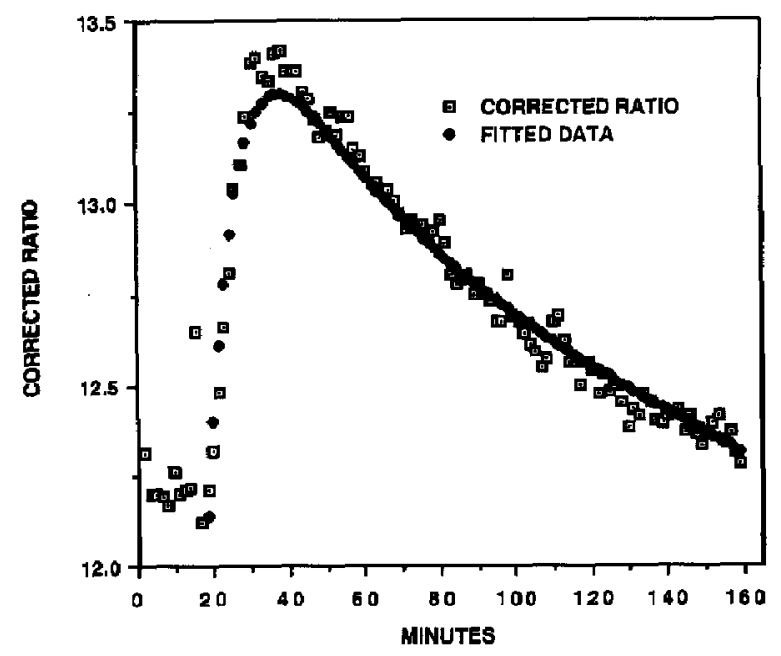

Figure 6. Ratio of ${ }^{13} \mathrm{CO}_{2} /{ }^{12} \mathrm{CO}_{2}$ in expired air from Charles River mice dosed orally with $175 \mathrm{mg} / \mathrm{kg}{ }^{13} \mathrm{C}$-methyl methionine. Data points are corrected ratios times 1000 and represent the average of four mice. (๑) Corrected ratios for expired air; (\$) fitted data with apparent rate constants, as described in Table 1. Fitted data are calculated from the model $\mathrm{R}=-17.973 \mathrm{e}^{\left(-.01384^{*} t\right)}$ $+2.066 e^{\left(-.038^{4} t\right)}+13.24 e^{\left(-.000457^{*} t\right)}$ where $e$ is the natural $\log$ and $t$ is time in minutes.

change in the isotopic ratio; there were two rate constants for formation and two for elimination. Rate constants are summarized in Table 1. Critical evaluation of the apparent differences requires a more objective means of determining the rate constants.

To determine if certain genetic disorders might have any influence upon the conversion of ${ }^{13} \mathrm{C}$-methyl me-

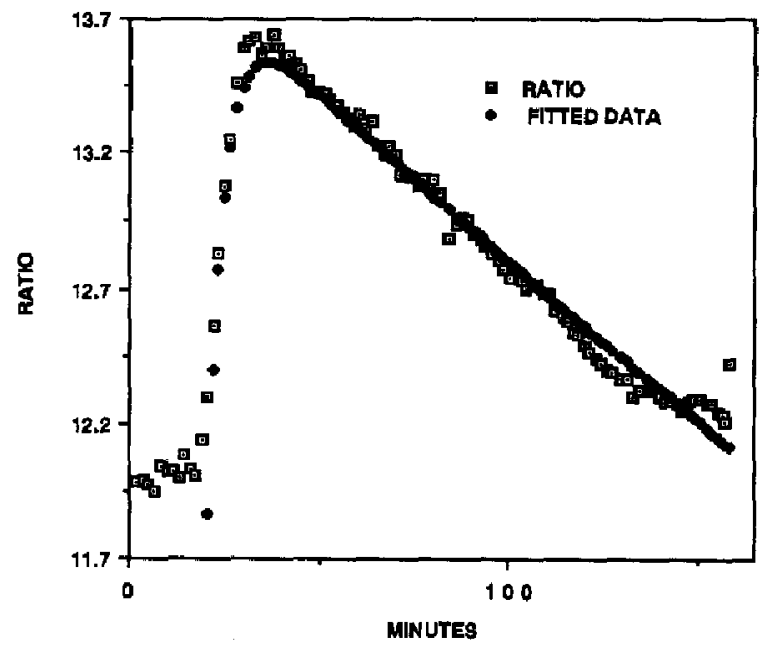

Figure 7. Ratio of ${ }^{13} \mathrm{CO}_{2} /{ }^{12} \mathrm{CO}_{2}$ in expired air from Charles River mice dosed intraperitoneally with $175 \mathrm{mg} / \mathrm{kg}{ }^{13} \mathrm{C}$-methy] methionine. Data points are corrected ratios times 1000 and represent the average of data from four mice. ( $\square$ ) Corrected ratios for expired air; $(\diamond)$ fitted data with apparent rate constants, as described in Table 1 . Fitted data are calculated from the model $R=-189.1011 \mathrm{e}^{\left(-.225^{*} t\right)}+14,0631 \mathrm{e}^{\left(-.000942^{*} t\right)}$ where $e$ is the natural $\log$ and $t$ represents time in minutes. thionine to ${ }^{13} \mathrm{CO}_{2}$, two mice were evaluated, one with short chain acyl-coenzyme $A$ dehydrogenase deficiency (BALB/CByJ) and the other normal (BALB/cBy). The animals were virtually identical in their metabolism of ${ }^{13} \mathrm{C}$-methyl methionine to $\mathrm{CO}_{2}$. Their rates of $\mathrm{CO}_{2}$ formation and elimination, though, were more similar to Charles River mice that were dosed intraperitoneally.

Human studies consisted of one control and one experimental subject, and so they serve primarily to demonstrate that the technique is applicable to humans. Human data shown in Figure 8 are from a black female who was diagnosed as manic-depressive, or bi-polar. Rates of formation, $K_{f}$, and the rates of elimination, $\mathrm{K}_{e}$, were different from the control subject (see Table 1). The control subject had two phases for ${ }^{13} \mathrm{CO}_{2}$ formation; the bi-polar subject only one. Only a single exponential phase for elimination was identified in each subject and it was longer than the terminal phase for elimination in mice.

\section{Discussion}

In this report we have described the measurement of isotopic ratios of ${ }^{13} \mathrm{CO}_{2} /{ }^{12} \mathrm{CO}_{2}$ in expired air following the administration of ${ }^{13} \mathrm{C}$-methyl methionine. The technique is unique in that it uses a quadrupole mass spectrometer and provides real-time analysis such that with improvements in data reduction, results (or diagnosis) could be available in hours instead of days or weeks. Of significant importance is the availability of a mouse model for the study of metabolic processes that are important in humans. The potential for diagnosis of a variety of metabolic disorders has been well illustrated by other investigators [3-7]. The alternate measurement of an internal standard and the sample eliminated many of the problems previously associated with the quadrupole, such as changes in sensitivity and a drift in the mass axis. While the quadrupole does not match the isotope ratio mass spectrometer in terms of absolute sensitivity and specificity, it is nonetheless effective for metabolism studies described here that are of interest to biologists. Of particular importance is the direct analysis of expired air that makes the collection of samples unnecessary, and the small sample size required makes it possible to evaluate small animals individually and in real time. This should make the technique attractive for the development of small animal models for the study of metabolic disorders and the application of those studies to the diagnosis and treatment of metabolic disorders in neonates. Because the data are available almost immediately, diagnosis should be more rapid and treatment more timely.

The assumptions underlying our experiments are quite simple: first, $\mathrm{CO}_{2}$ that is formed as a result of metabolism enters the $\mathrm{CO}_{2}$ pool(s) and is eliminated in expired air in proportion to its concentration in that pool(s); second, the overall rate of production of $\mathrm{CO}_{2}$ 
Table 1. Summary of results with apparent rate constants and half lives.

\begin{tabular}{|c|c|c|c|c|c|}
\hline EXPERIMENT & DOSE $\mathrm{mg} / \mathrm{kg}$ & $\overline{K_{F 1}\left(\min ^{-1}\right) t_{1 / 2}(h)}$ & $\mathrm{K}_{\mathrm{F} 2}\left(\min ^{-1}\right) \mathrm{t}_{1 / 2}(\mathrm{~h})$ & $K_{E 1}\left(\min ^{-1}\right) t_{1 / 2}(h)$ & $K_{E 2}\left(\min ^{-1}\right) t_{1 / 2}(h)$ \\
\hline Human WM & 15 & $12.46 \times 10^{2}$ & $9.05 \times 10^{-2}$ & $\overline{-}$ & $3.33 \times 10^{-4}$ \\
\hline Control & & $0.09 \mathrm{~h}$ & $0.13 \mathrm{~h}$ & & $34.67 \mathrm{~h}$ \\
\hline Human BF & 15.7 & $6.61 \times 10^{2}$ & - & - & $2.79 \times 10^{4}$ \\
\hline Bi-polar & & $0.17 \mathrm{~h}$ & & & $41.46 \mathrm{~h}$ \\
\hline Mouse & 175 & $11.84 \times 10^{-2}$ & -. & $3.78 \times 10^{-2}$ & $4.57 \times 10^{-4}$ \\
\hline Low dose p.o. & & $0.098 \mathrm{~h}$ & & $0.31 \mathrm{~h}$ & $25.26 h$ \\
\hline Mouse & 175 & $22.50 \times 10^{2}$ & - & - & $9.42 \times 10^{-4}$ \\
\hline Low dose i.p. & & $0.05 \mathrm{~h}$ & & & $12.26 \mathrm{~h}$ \\
\hline Mouse & 350 & $42.05 \times 10^{-2}$ & $10.32 \times 10^{-2}$ & $27.40 \times 10^{-2}$ & $10.36 \times 10^{-4}$ \\
\hline High dose i.p. & & $0.002 \mathrm{~h}$ & $0.11 \mathrm{~h}$ & $0.42 \mathrm{~h}$ & $11.14 \mathrm{~h}$ \\
\hline Mouse & 175 & $20.38 \times 10^{-2}$ & - & - & $10.14 \times 10^{-4}$ \\
\hline $\begin{array}{l}\text { Low dose p.o. } \\
\text { BALB /c }\end{array}$ & & $0.057 \mathrm{~h}$ & & & $11.39 \mathrm{~h}$ \\
\hline
\end{tabular}

$B F=$ black female; $K_{F 1}$ and $K_{F 2}$ are the apparent rate(s) of formation while $K_{E 1}$ and $K_{E 2}$ are the apparent rate(s) of elimination; WM $=$ white male.

does not change remarkably during the course of the experiment, and finally, the conditions for metabolism and elimination are all first order. While these assumptions may not be true for all substrates and doses, based upon the conditions described herein, they do appear to hold for the metabolism of methionine.

Upon reflection it is clear that the selection of a substrate is critical, because some carbons are not converted to $\mathrm{CO}_{2}$. Furthermore, some $\mathrm{CO}_{2}$ is formed but is not eliminated in the expired air. Such losses in the urine, feces, and sweat are expected to be not only small, but proportional to the loss in expired air. Of more concern is the "natural" fluctuation of the iso-

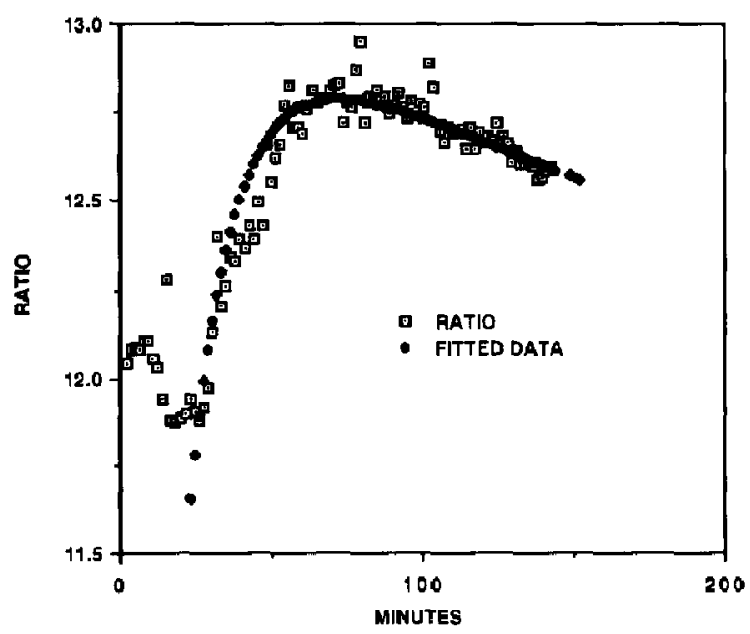

Figure 8. Ratio of ${ }^{13} \mathrm{CO}_{2} /{ }^{12} \mathrm{CO}_{2}$ in expired air from a bi-polar (manic-depressive) black female who received $1 \mathrm{~g}{ }^{13} \mathrm{C}$-methyl methionine in distilled water. (a) Corrected ratios for expired air; ( ) fitted data with apparent rate constants, as described in Table 1. Fitted data were calculated from the model $\mathrm{R}=$ $-6.148 e^{\left(-.066^{*} t\right)}+13098 e^{\left(000279^{*}\right)}$ where $p$ represents the natural $\log$ and $t$ is the time in minutes. topic ratio in expired air. According to Schoeller et al. [8], such fluctuations occur in the elimination of ${ }^{13} \mathrm{CO}_{2}$ during the course of the experiment as a result of the body's use of different energy pools. These fluctuations may limit the ultimale precision for measurement of the ${ }^{13} \mathrm{CO}_{2} /{ }^{12} \mathrm{CO}_{2}$ ratio in expired air following tracer doses of labeled substrate, but such precision is not necessary for the metabolic events described herein. For example, in the control experiments in which no labeled substrate was administered, the ratio of ${ }^{13} \mathrm{CO}_{2} /{ }^{12} \mathrm{CO}_{2}$ at rest was not subject to dramatic shifts, and the ratio of the two major isotopes $45 / 44$ was statistically stable for individual subjects. We found that the average ratios for individual untreated control animals over the course of $2 \mathrm{~h}$ were statistically different. While we cannot rule out real differences in the ratios, the fact that the animals were all from the same litter and were all housed together suggests that the differences were more likely due to small differences in the machine or in the ambient conditions during the different experiments. While those differences are statistically significant as a result of good analytical precision, they are really quite small when compared with the differences occurring after administration of labeled methionine.

Irving et al. [9] suggested a four-compartment model to describe the elimination of ${ }^{13} \mathrm{CO}_{2}$ following the administration of $\mathrm{NaH}^{13} \mathrm{CO}_{3}$ to humans. As they pointed out, the changes in $\mathrm{CO}_{2}$ elimination from day to day were such that comparison is best made between or among populations. The similarity of mice to humans is striking in this regard. We have also found the possibility of multiple compartments, but most likely not the same as those reported by Irving because we collected more data points over a much shorter time. Extending our methodology to longer time periods is technically possible, but requires a different experimental design to deal with the interruption of resting metabolism that is expected to occur. 
The method does not account for all of the possible isotopic variants of $\mathrm{CO}_{2}$ that might be formed, but neither does it become encumbered in methodology, which would make it unavailable to most laboratories and/or unattractive to many clinical applications. If the assumptions are extended to the other isotopes, it is clear that they will be formed in the same proportion as $m / z 45$, which corresponds to ${ }^{13} \mathrm{C}^{16} \mathrm{O}_{2}$.

Limiting consideration of the metabolic processes to the formation and elimination of ${ }^{13} \mathrm{CO}_{2}$ allowed us to focus on the measurement of isotopic ${ }^{13} \mathrm{CO}_{2} /{ }^{12} \mathrm{CO}_{2}$ ratios rather than the mechanism of metabolism. We were able to follow the formation of ${ }^{13} \mathrm{CO}_{2}$ over time, which provided information on the turnover of ${ }^{13} \mathrm{C}$ methyl methionine.

In those experiments in which labeled methionine was administered, the changes in the isotopic ratios were obvious and of a continuous nature. Inspection of the curves also suggested that random variation was small. In some experiments short-term changes in the isotopic ratio, or bursts of apparent metabolic activity, occurred that lasted only a few minutes. These "bumps" are invisible in most experiments with fewer data points because they appear during the time in which data are collected at increasingly longer intervals. These bumps have not yet been evaluated critically, but ignoring them may change the apparent rate constants slightly, and reduce the goodness of fit for the model. They may indeed be magnified manifestations of those internal fluctuations described by Schoeller et al. [8].

Mice used in these experiments have exhibited no apparent ill effects, but the influence of restraint per se is unknown. A different experimental design is required to determine the contribution of restraint to the metabolism of the substrates employed.

Israelstam et al. [6] reported that schizophrenics and depressed patients had qualitatively and quantitatively different rates of elimination for ${ }^{14} \mathrm{CO}_{2}$ following the administration of ${ }^{14} \mathrm{C}$-methyl methionine. While we have not yet confirmed that report, we have demonstrated that the evolution of ${ }^{13} \mathrm{CO}_{2}$ from a labeled substrate can be monitored externally in real time through evaluation of the expired air with adequate sensitivity and specificity. Additional studies are in progress to further evaluate the environmental and metabolic conditions affecting the conversion of methionine and other substrales to $\mathrm{CO}_{2}$.

\section{Acknowledgments}

This study was supported in part by the Schizophrenia Research Program and the NIH/Coca Cola Summer Fellows program for minority students. BALB/cBy mice were provided by Dr. Phil Wood of the Department of Comparative Medicine at UAB. Suggestions by Dr. Ken Olsen of the Department of Nutrition at $\mathrm{UAB}$ and Dr. Jeanette Adams of the Department of Chemistry at Emory University were most helpful and are greatly appreciated.

\section{References}

1. Duchesne, J; van de Vors, A. C.R. Acad. Sci. Ser. D 1968, 266 , 522

2. Jacobson, B. S.; Smith, B. M.j Jacobson, A. V. Biochem, Biophys. Res. Commun. 1972, 47, 398.

3. Shreeve, W. W.; Shoop, I. D.; Ott, D. G.; McInteer, B. B. Gastroenterology 1976, 71, 98-101.

4. Schwabe, A. D.; Bennett, L. R.; Bowman, L. P. I. Appl. Physiol. 1964, 19, 334

5. Graham, D. Y.; Evans, D. J. Jr.,; Alpert, L. C.; Klein, $P_{+}$D.; Evans, D. G.; Opekun, A. R.; Boutton, T. W. Lancet 1987, May 23, 1174-1177.

6. Israelstam, D. M.; Sargent, T.; Finley, N. N.; Winchell, H. S.; Fish, M. B.; Motto, J.; Pollycove, M.; Johnson, A. I. Psych. Res. $1970,17,185-190$.

7. Furner, R. L.; Ghanta, V. K.; Hiramoto, R. Pharmacologist $1983,25,3$.

8. Schoeller, D. A,; Schneider, J. F; Solomons, N. W.; Watkins, J. B.; Klein, P. D. I. Lab. Clin. Med. 1977, 90, 412-421.

9. Irving, C. S.; Wong, W. W.; Shulman, R. J.; O'Brian Smith, E.; Klein, P. D. Am. J. Physiol. 1983, 245 (Regulatory Integrative Comp. Physiol 14), RI90-202.

10. Nelson, P. R. J. Am. Soc. Mass. Spectrom. 1991, 2, 427-431.

11. Furner, R. L.; Mellett, L. B. Lab. Animal Sci. 1975, 25, 648-649. 